\title{
Radioactive analysis and radiological hazards of sand in Weifang, China
}

\author{
N. Yin, X. Lu* ${ }^{*}$ Y. Li
}

School of Tourism and Environment, Shaanxi Normal University, Xi'an 710062, P.R. China

\section{Short report}

\author{
*Corresponding author: \\ Dr. Xinwei $L u$, \\ Fax: +862985303883 \\ E-mail: \\ luxinwei@snnu.edu.cn \\ Revised: Aug. 2016 \\ Accepted: Sept. 2016 \\ Int. J. Radiat. Res., April 2017; \\ 15(2): 225-228 \\ DOI: 10.18869 /acadpub.ijrr.15.2.225
}

\section{ABSTRACT}

Background: The activity concentrations of ${ }^{226} \mathrm{Ra},{ }^{232} \mathrm{Th}$ and ${ }^{40} \mathrm{~K}$ in sand used as building material in Weifang of China were investigated for evaluating the radiation hazard. Materials and Methods: Sand samples were collected from Weifang and their radioactivity levels were measured using gamma-ray spectrometry. The radiation hazard for residents was assessed by radium equivalent activity $\left(R a_{\text {eq }}\right)$, indoor air absorbed dose rate $(D)$, annual effective dose $(A E D)$ and excess lifetime cancer risk (ELCR). Results: The activity concentrations of ${ }^{226} \mathrm{Ra},{ }^{232} \mathrm{Th}$ and ${ }^{40} \mathrm{~K}$ ranged from 11.7 to $23.0,33.6$ to 126.1 and 353.2 to $924.8 \mathrm{~Bq} \mathrm{~kg}{ }^{-1}$ with averages of $15.5,70.3$ and $802.9 \mathrm{~Bq} \mathrm{~kg}^{-1}$, respectively. All $\mathrm{Ra}_{\text {eq }}$ values were lower than the limit of $370 \mathrm{~Bq} \mathrm{~kg}$. The mean value of $D$ was higher than the world population-weighted average of $84 \mathrm{nGy} \mathrm{h}^{-1}$, while the mean $A E D$ and ELCR values were below the internationally accepted values. Conclusions: The use of sand in construction of dwellings is considered to be safe for inhabitants.

Keywords: Gamma-ray spectroscopy, natural radioactivity, radiation hazard, excess lifetime cancer risk, sand.

\section{INTRODUCTION}

Natural radionuclides $226 \mathrm{Ra},{ }^{232} \mathrm{Th}$ and ${ }^{40} \mathrm{~K}$ widely spread in rock, soil, sediment and building materials (1-3). Building materials are the main source of indoor gamma radiation besides terrestrial and cosmic radiations as individuals spend about $80 \%$ lifetime at home and/or office (2). ${ }^{226} \mathrm{Ra}, \quad{ }^{232} \mathrm{Th}$ and ${ }^{40} \mathrm{~K}$ concentrations in building materials depend on their geochemical compositions (4-6). It is important to measure the activity concentrations of ${ }^{226} \mathrm{Ra},{ }^{232} \mathrm{Th}$ and ${ }^{40} \mathrm{~K}$ in building materials from different places for estimating the radiological hazards to residents.

Weifang, the world's kite metropolis, is located at the east of Shandong province of China (figure 1), with a population of approximately $9,086,000$. The aims of this work were to measure the activity concentrations of ${ }^{226} \mathrm{Ra},{ }^{232} \mathrm{Th}$ and ${ }^{40} \mathrm{~K}$ in sand used as building materials in Weifang using gamma-ray spectrometry and to assess the corresponding radiological hazards to individuals using radium equivalent activity, indoor air absorbed gamma dose rate, annual effective dose and excess lifetime cancer risk. The obtained results were compared with the recommended values and the similar studies carried out in other areas.

\section{MATERIALS AND METHODS}

\section{Samples}

Thirteen sand samples were collected randomly from local supplies and construction sites of Weifang, China. Each sample was ground to a finer power with a particle size $<0.16 \mathrm{~mm}$ and dried at $110^{\circ} \mathrm{C}$ for $24 \mathrm{~h}$ in an oven to ensure that moisture was completely removed (7-10). The dried samples were weighted and stored in gas-tight, radon impermeable and polyethylene containers to prevent the escape of ${ }^{222} \mathrm{Rn}$ and ${ }^{220} \mathrm{Rn}$ from the samples ${ }^{(8)}$. The containers were 
kept more than 4 weeks to ensure radioactive equilibrium $(7,8)$.

\section{Measurement of radioactivity}

The activity concentrations of ${ }^{226} \mathrm{Ra},{ }^{232} \mathrm{Th}$ and ${ }^{40} \mathrm{~K}$ in the sand were determined using a $3 \times 3$ inch $\mathrm{NaI}(\mathrm{Tl})$ gamma-ray spectrometric system with $>8 \%$ energy resolution $\left({ }^{137} \mathrm{Cs} 661.6 \mathrm{keV}\right.$ ) (7). The detector, maintained in a lead cylindrical shield of $10.5 \mathrm{~cm}$ thickness and $38 \mathrm{~cm}$ height, was coupled to a 1024 multichannel pulse height analyzer and the system was calibrated for the gamma-energy range from $50 \mathrm{keV}$ to $3.2 \mathrm{MeV}$ (7). The activity of ${ }^{232} \mathrm{Th}$ was measured by $238.6 \mathrm{keV}$ and $2614 \mathrm{keV}$ gamma rays emitted from ${ }^{212} \mathrm{~Pb}$ and ${ }^{208} \mathrm{Tl}$, respectively. The activity ${ }^{226} \mathrm{Ra}$ was measured by 609.3 and $1764.5 \mathrm{keV}$ gamma rays emitted from ${ }^{214} \mathrm{Bi}$, whereas ${ }^{40} \mathrm{~K}$ activity was measured directly through its gamma ray energy peak of $1460.8 \mathrm{keV}{ }^{(7-9)}$. The standard sources of ${ }^{226} \mathrm{Ra}$ and ${ }^{232} \mathrm{Th}$ were prepared using known activity contents and mixing with the matrix material of phthalic acid powder (8). The standard source of ${ }^{40} \mathrm{~K}$ used analytical grade potassium chloride (99.99\% purity) of known mass and the same geometry. All samples were counted for $300 \mathrm{~min}$ and each sample was counted twice before an average was calculated. The relative errors of twice measurement data for ${ }^{226} \mathrm{Ra}$, ${ }^{232} \mathrm{Th}$ and ${ }^{40} \mathrm{~K}$ in all samples are $<5 \%$. Excel 2010 and SPSS 19.0 for windows were used to analyze the data.

\section{RESULTS AND DISCUSSION}

The activity concentrations of ${ }^{226} \mathrm{Ra},{ }^{232} \mathrm{Th}$ and ${ }^{40} \mathrm{~K}$ in the investigated sand samples ranged from 11.7 to 23.0, 33.6 to 126.1 and 353.2 to $924.8 \mathrm{~Bq} \mathrm{~kg}^{-1}$ with averages of $15.5,70.3$ and $802.9 \mathrm{~Bq} \mathrm{~kg}^{-1}$, respectively, as shown in figure 2 . The average concentration of ${ }^{226} \mathrm{Ra}$ in the sand samples was lower than the corresponding average value of Chinese soil (37.6 $\left.\mathrm{Bq} \mathrm{kg}^{-1}\right)$ and the worldwide population-weighted average value (32 $\left.\mathrm{Bq} \mathrm{kg}^{-1}\right)$ in soil (2). The mean values of ${ }^{232} \mathrm{Th}$ and ${ }^{40} \mathrm{~K}$ concentrations of sand from Weifang were higher than the average values of Chinese soil (54.6 and $584 \mathrm{~Bq} \mathrm{~kg}^{-1}$, respectively)

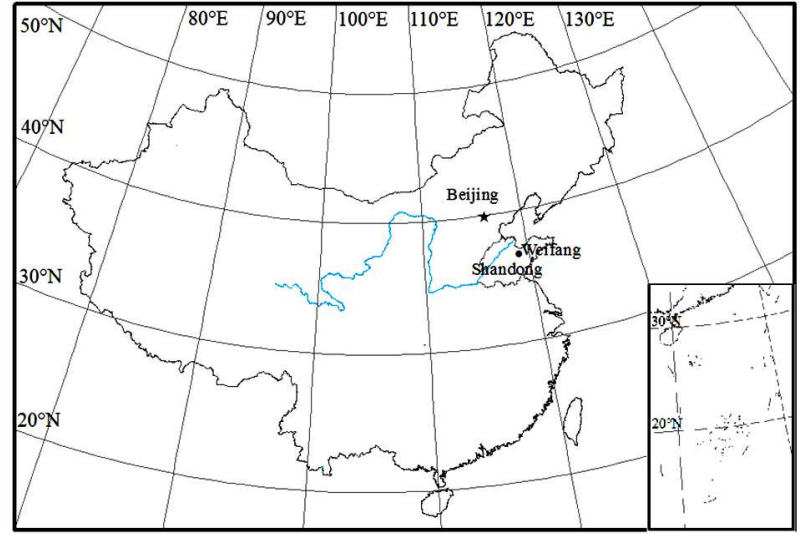

Figure 1. The location of Weifang, China.

and the worldwide population-weighted average value in soil (45 and $420 \mathrm{~Bq} \mathrm{~kg}^{-1}$, respectively) (2). ${ }^{40} \mathrm{~K}$ is the largest contributor to the total activity, which accounts for approximately $84-93 \%$ of the total activity. Table 1 shows the comparison of the activity concentrations of ${ }^{226} \mathrm{Ra},{ }^{232} \mathrm{Th}$ and ${ }^{40} \mathrm{~K}$ in sand of Weifang with other reports (3,5-13). The natural radioactivity level in sands from different areas are not uniform, which would be due to the differences of their sources and chemical compositions.

Radium equivalent activity $\left(\mathrm{Ra}_{\mathrm{eq}}\right){ }^{(3)}$, indoor air absorbed dose rate $(D)^{(14)}$, annual effective dose $(A E D)^{(2)}$ and excess lifetime cancer risk $(E L C R)^{(15)}$ were calculated to assess radiological hazards associated with the sand samples used as building materials. The duration of life in the calculation of $E L C R$ is Chinese datum (75 years) (http://en.worldstat.info/Asia/China). The Ra values in the sand, ranging from 90.4 to $264.3 \mathrm{~Bq}$ $\mathrm{kg}^{-1}$ with an average of $177.9 \mathrm{~Bq} \mathrm{~kg}^{-1}$ (figure 2), were lower than the allowed limit of $370 \mathrm{~Bq} \mathrm{~kg}^{-1}$ in building materials for safe use recommended by Organization for Economic Cooperation and Development (2). The values of $D$ and $A E D$ for all studied sand samples in Weifang ranged from 79.14 to $223.17 \mathrm{nGy} \mathrm{h}^{-1}$ with an average of $155.85 \mathrm{nGy} \mathrm{h}^{-1}$ and from 0.39 to $1.09 \mathrm{mSv} \mathrm{y}^{-1}$ with an average of $0.76 \mathrm{mSv} \mathrm{y}^{-1}$, respectively (figure 3). The values of $D$ and $A E D$ in the most sand samples (except one sample) were higher than the worldwide average value (84 $\mathrm{nGy} \mathrm{h}^{-1}$ and $0.41 \mathrm{mSv}^{-1}$ ) and the average value of China (99 $\mathrm{nGy} \mathrm{h}^{-1}$ and $0.49 \mathrm{mSv} \mathrm{y}^{-1}$ ) (2), while the values 
of $A E D$ in the most sand samples (except one sample) were lower than the recommended limit of $1 \mathrm{mSv}^{-1}$ (14). The values of ELCR for the investigated samples ranged from $1.46 \times 10^{-3}$ to $4.09 \times 10^{-3}$ with an average of $2.87 \times 10^{-3}$. According to the above-mentioned recommended limit $\left(1 \mathrm{mSv} \mathrm{y}^{-1}\right)$ of $A E D$, the maximum ELCR should not exceed $3.75 \times 10^{-3}$ for indoor exposure. The average ELCR for the investigated sand samples is less than this maximum.

Table 1. Comparison of activity concentrations and radium equivalent activity $\left(\mathrm{Ra}_{\mathrm{eq}}\right)$ in sands from different areas.

\begin{tabular}{|c|c|c|c|c|}
\hline \multirow{2}{*}{ Areas } & \multicolumn{3}{|c|}{ Activity concentration $\left(\mathrm{Bq} \mathrm{kg}^{-1}\right)$} & \multirow{2}{*}{$\operatorname{Ra}_{\text {eq }}\left(B q \mathrm{~kg}^{-1}\right)$} \\
\hline & ${ }^{226} \mathrm{Ra}$ & ${ }^{232} \mathrm{Th}$ & ${ }^{40} \mathrm{~K}$ & \\
\hline Xining, China ${ }^{(7)}$ & 21.5 & 32.7 & 764.1 & 121.7 \\
\hline Urumqi, China $^{(8)}$ & 22.4 & 25.1 & 789.3 & 119 \\
\hline Baotou, China $^{(9)}$ & 16 & 26 & 736 & 110 \\
\hline Punjab, Pakistan ${ }^{(10)}$ & 24 & 39 & 462 & 112 \\
\hline Bangladesh ${ }^{(11)}$ & 14.1 & 25.0 & 158.4 & 62.1 \\
\hline Malaysia $^{(12)}$ & 60 & 13 & 750 & 136 \\
\hline India ${ }^{(13)}$ & 43.7 & 64.4 & 455.8 & 170.8 \\
\hline Namakkal, India ${ }^{(3)}$ & 2.27 & 21.72 & 352.8 & 59.68 \\
\hline Najaf, Iraq ${ }^{(5)}$ & 43.57 & 1.98 & 135.02 & 56.54 \\
\hline Karbala, Iraq ${ }^{(5)}$ & 44.21 & 2.06 & 108.73 & 55.26 \\
\hline Pakistan $^{(6)}$ & 30.5 & 53.2 & 531.3 & 143.8 \\
\hline Weifang, China (Present study) & 15.5 & 70.3 & 802.9 & 177.9 \\
\hline
\end{tabular}

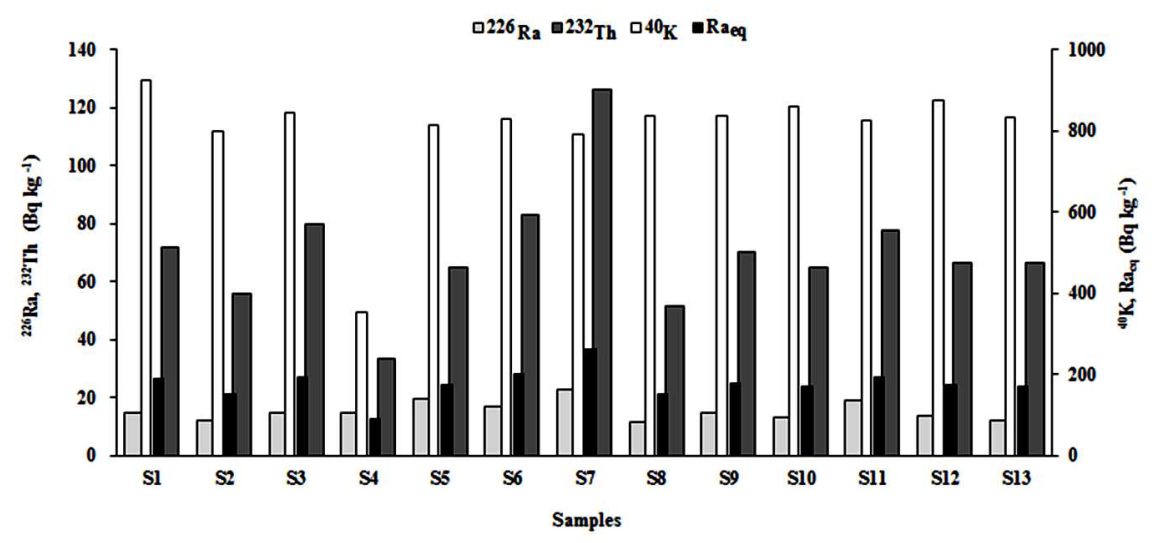

Figure 2. The activity concentrations of ${ }^{226} \mathrm{Ra},{ }^{32} \mathrm{Th}$ and ${ }^{40} \mathrm{~K}$ and radium equivalent activity $(\mathrm{Ra}$ eq $)$ in the sand samples.

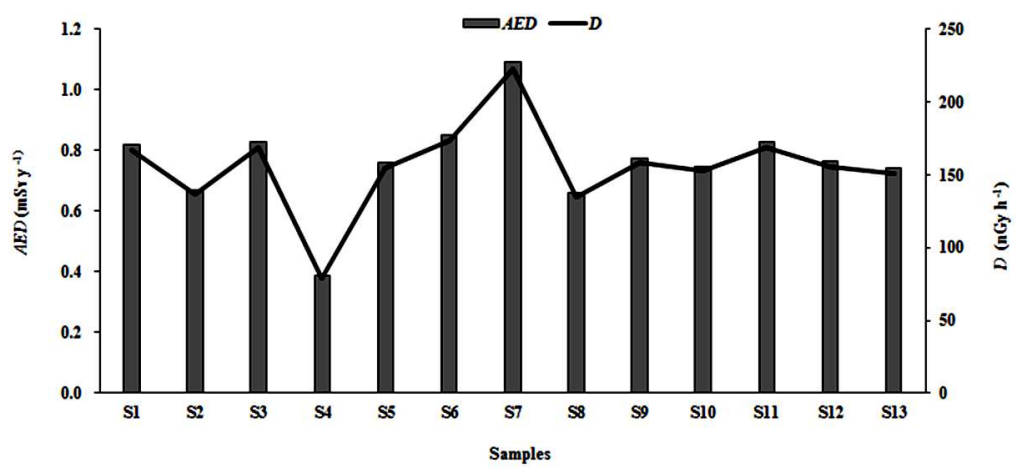

Figure 3. The absorbed dose rate indoor $(D)$ and annual effective dose $(A E D)$ in the sand samples. 


\section{CONCLUSION}

The mean concentrations of ${ }^{232} \mathrm{Th}$ and ${ }^{40} \mathrm{~K}$ in sand from Weifang of China were higher than, while the mean concentration of ${ }^{226} \mathrm{Ra}$ was lower than the average concentration of Chinese soil and the worldwide population-weighted average value in soil. From the analysis of radiological parameters, one can conclude that sand samples collected from Weifang, China can be safely used as building materials and do not pose significant radiation hazards to inhabitants.

\section{ACKNOWLEDGEMENTS}

This work was supported by the Fundamental Research Funds for the Central Universities through Grants GK201601009. Gratitude is expressed to $S$ Zhuang and C Shi for their helps with the samples preparation and the experiments. The authors also thank Editor-inChief Prof. Hossein Mozdarani and anonymous reviewers for their insightful suggestion and critical reviews of the manuscript.

\section{Conflict of interest: Declared none.}

\section{REFERENCES}

1. Manjunatha S, Jayasheelan A, Venkataranabauag $P$ (2013) Study of distribution of ${ }^{226} \mathrm{Ra},{ }^{232} \mathrm{Th}$ and ${ }^{40} \mathrm{~K}$ in different rock formations and their dose estimation in and around Chickmagalur, India. Int J Radiat Res, 11: 183-187.

2. UNSCEAR-United Nations Scientific Committee on the Effects of Atomic Radiation (2000) Sources and effects of Ionizing radiation. Report to the General Assembly, with Scientific Annexes. New York: United Nations Publications.

3. Ravisankar R, Vanasundari K, Chandrasekaran A, Rajalakshmi A, Suganya M, Vijayagopal P, Meenakshisundaram
V (2012) Measurement of natural radioactivity in building materials of Namakkal, Tamil Nadu, India using gamma-ray spectrometry. Appl Radiat Isot, 70: 699-704.

4. Rafique M, Rehman H, Matiullah, Malik F, Rajput MU, Rahman SU, Rathore MH (2011) Assessment of radiological hazards due to soil and building materials used in Mirpur Azad Kashmir; Pakistan. Int J Radiat Res, 9(2): 77-87.

5. Hussain HH, Hussain RO, Yousef RM, Shamkhi Q (2010) Natural radioactivity of some local building materials in the middle Euphrates of Iraq. J Radioanal Nucl Chem, 284: 4347.

6. Malik F, Matiullah, Akram M, Rajput MU (2011) Measurement of natural radioactivity in sand samples collected along the bank of rivers Indus and Kabul in northern Pakistan. Radiat Protect Dosim, 143: 97-105.

7. Chao S, Lu X, Zhang M, Pang L (2014) Natural radioactivity level and radiological hazard assessment of commonly used building material in Xining, China. J Radioanal Nucl Chem, 300: 879-885.

8. Ding X, LuX, Zhao C, Yang G, Li N (2013) Measurement of natural radioactivity in building materials used in Urumqi, China. Radiat Protect Dosim, 155: 374-379.

9. Zhao C, Lu X, Li N, Yang G (2012) Natural radioactivity measurements of building materials in Baotou, China. Radiat Protect Dosim, 152: 434-437.

10. Rahman SU, Rafique M, Jabbar A, Matiullah (2013) Radiological hazards due to naturally occurring radionuclides in the selected building materials used for the construction of dwellings in four districts of the Punjab province, Pakistan. Radiat Protect Dosim, 153: 352-360.

11. Chowdhury MI, Alam MN, Ahmed AKS (1998) Concentration of radionuclides in building and ceramic materials of Bangladesh and evaluation of radiation hazard. J Radioanal Nucl Chem, 231: 117-122.

12. Ibrahim $N$ (1999) Natural activities of ${ }^{238} \mathrm{U},{ }^{232} \mathrm{Th}$ and ${ }^{40} \mathrm{~K}$ in building materials. J Environ Radioact, 43: 255-258.

13. Kumar V, Ramachandran TV, Prasad R (1999) Natural radioactivity of Indian building materials and by products. App/ Radiat Isot, 51: 93-96.

14. EC-European Commission (1999) Radiation protection 112. Radiological protection principles concerning the natural radioactivity of building materials. Directorate-General Environment, Nuclear Safety and Civil Protection.

15. Taskin H, Karavus M, Ay P, Topuzoglu A, Hidiroglu S, Karahan, $G$ (2009) Radionuclide concentrations in soil and lifetime cancer risk due to the gamma radioactivity in Kirklareli, Turkey. J Environ Radioact, 100: 49-53. 